\title{
Nietzsche: da análise psicológica à fórmula da décadence ${ }^{*}$
}

\author{
Scarlett Marton**
}

Resumo: Tendo esclarecido a concepção nietzschiana de psicologia, este artigo persegue um duplo objetivo: de um lado, investigar a análise psicológica dos fenômenos da décadence e, de outro, elucidar o que significa a expressão "fórmula da décadence" nos textos de 1888.

Palavras-chave: psicologia, valor, avaliação, décadence.

\footnotetext{
* Tradução brasileira da conferência intitulada "I testi del 1888: dall'analisi psicológica alla formula della décadence", proferida na XV Edizione del Seminario Permanente Nietzscheano, na Università Ca'Foscari, em Veneza, em 20 de dezembro de 2018

** Universidade de São Paulo, São Paulo, SP, Brasil.

ORCID https://orcid.org/0000-0002-6869-3371

Correio eletrônico: smarton@usp.br
} 
Marton, S.

O diagnóstico dos fenômenos da décadence, termo que Nietzsche faz questão de grafar em francês, aparece com clareza em seus textos de 1888. Não são poucos os comentadores que sublinham a importância de aproximar quatro livros por ele composto no último ano em que se manteve intelectualmente ativo. $\mathrm{O}$ próprio filósofo considerou o Crepúsculo dos Ídolos o "irmão gêmeo do Caso Wagner"; concebeu de início Ecce Homo como um apêndice do Crepúsculo dos ídolos; transcreveu os capítulos do Crepúsculo dos ídolos ao mesmo tempo que vinte e quatro parágrafos de $O$ Anticristo. Essas duas últimas obras, aliás, emergiram de suas anotações tendo em vista a elaboração da Vontade da Potência, um projeto a que se dedicou de setembro de 1885 até o final de $1888 .^{2}$

Não há dúvida de que, embora o termo décadence apareça pela primeira vez numa anotação póstuma do outono de 1883 (Nachlass/FP 1883, 16 [5], KSA 10.497), ele está presente de forma recorrente nos textos publicados ou destinados à publicação em 1888. Tomando como ponto de partida passagens do Caso Wagner, Crepúsculo dos ídolos, $O$ Anticristo e Ecce Homo, conto, de início, examinar a concepção nietzschiana de psicologia. Espero, em seguida, esclarecer a análise psicológica que Nietzsche faz dos fenômenos da décadence nessas obras. Por fim, atentando para o seu combate contra o declínio da humanidade, persigo o propósito de elucidar o que ele entende pela expressão "fórmula da décadence".

1 Carta a Constantin Georg Naumann de 7 de setembro de 1888, KSB 8.411 (tradução de Scarlett Marton, designada a partir de agora SM); $c f$. também carta a Heinrich Köselitz de 12 setembro de 1888, KSB 8.417.

2 Reconstruindo a gênese do Crepúsculo dos Ídolos nesse contexto, Mazzino Montinari bem mostrou que a publicação do livro constitui a prova de que Nietzsche abandonou, de fato, o projeto da Vontade de potência no final de 1888. Cf. Montinari, 1984, pp. 69-79. Na página 70, Montinari escreve: "A história do aparecimento do Crepúsculo dos ídolos é ao mesmo tempo a história das intenções literárias de Nietzsche quanto a todo o material que havia reunido até esse momento, tendo em vista a "Vontade de Potência'."

46 | Cad. Nietzsche, Guarulhos/Porto Seguro, v.41, n.2, p. 45-62, maio/agosto, 2020. 
Nos textos de 1888, várias são as passagens em que Nietzsche se autodenomina psicólogo. Numa delas, é explícito:

Que, nos meus escritos, fala um psicólogo sem igual, é talvez a primeira constatação a que chega um bom leitor - um leitor tal como mereço e que me lê como os bons filólogos de outrora liam Horácio. (EH, Por que escrevo livros tão bons, 5, KSA 6.305 (SM) $)^{3}$

Para atender à sua expectativa, procuremos esclarecer o que entende por "psicologia", tomando em consideração o primeiro capítulo do Crepúsculo dos ídolos. ${ }^{4}$ Na primeira sentença, ele afirma: "A ociosidade é o começo de toda psicologia". Mas é preciso levar em conta o fato de que, imediatamente depois, levanta a questão: "Como? A psicologia seria - um vício?" (GD/CI, Sentenças e setas, 1, KSA 6.59 (SM) $)^{5}$ Numa primeira abordagem, essas frases poderiam nos levar a pensar que Nietzsche faz aqui uma crítica da psicologia tradicionalmente concebida como o estudo dos fenômenos intelectuais e morais. ${ }^{6}$ Essa concepção, que se impôs graças ao trabalho de

$3 C f$. EH/EH, Por que sou um destino, 5, KSA 6.369. Vale lembrar que o livro Nietzsche contra Wagner apresenta o subtítulo "Dossiê de um psicólogo" e que, inicialmente, Crepúsculo dos ídolos foi intitulado "Lazer de um psicólogo". Cf. também GM/GM III, 19 e 20, KSA 5.384s.

4 Bem sabemos que foi graças a uma sugestão Heinrich Köselitz que Nietzsche decidiu mudar o título de sua obra. $C f$. carta a Heinrich Köselitz de 27 de setembro de 1888, KSB 8.443.

5 Cf. também Nachlass /FP 1887-1888, 11 [107], KSA 13.51 (SM), onde podemos ler: "A ociosidade é o começo de toda filosofia. - Por conseguinte, - a filosofia é um vício?" Esse fragmento póstumo e a primeira sentença do capítulo "Sentenças e setas" do Crepúsculo dos ídolos apresentam exatamente a mesma estrutura; a única diferença entre as duas passagens reside no emprego do termo "filosofia" no fragmento póstumo, que será substituído pelo vocábulo "psicologia" no livro. Esse fato contribui para defender a ideia de que Nietzsche concebe a psicologia como o núcleo de seu empreendimento filosófico.

6 Christian Wolff foi um dos primeiros a considerar a psicologia uma disciplina específica. Testemunha e cúmplice do processo geral de naturalização que então se iniciava, ele se dedicou a mostrar que a psicologia estava mais distante das questões sobre a origem do universo que dos problemas acerca da interação do homem com o que o rodeava. Se contribuiu para desvincular a psicologia das preocupações de ordem cósmica, continuou a fundá-la na metafísica. $C f$. Wolff, 1972. 
Marton, S.

Christian Wolff, tomava como ponto de partida a noção leibniziana de alma, entendida como uma substância simples e incorpórea, capaz de representar o mundo. Suas representações podiam ser perfeitas ou imperfeitas, se plenamente adequadas ou não. Quando claramente conhecidas, as ideias de perfeição e imperfeição, por sua vez, engendravam as de bem e mal. Concebida dessa maneira, a psicologia constituía a base, por assim dizer, dos juízos de realidade e dos juízos de valor. Intimamente ligada à lógica e à moral, ela encontrava o seu fundamento na metafísica.

Importa notar que, em seus textos, Nietzsche se lança num trabalho permanente de questionamento do essencialismo. Nessa primeira sentença do capítulo "Sentenças e setas" do Crepúsculo dos ídolos, ele poderia muito bem estar considerando a concepção tradicional de psicologia como sintomática de uma maneira de pensar que seria viciosa. Mas é revelador o fato de fazer com que a pergunta: "Como? A psicologia seria - um vício?" seja precedida pela afirmação "A ociosidade é o começo de toda psicologia". A palavra "ociosidade" evoca o título inicialmente escolhido para o texto que se tornaria o Crepúsculo dos ídolos. A esse primeiro título, o autor ainda faz referência no prefácio do livro, quando afirma que ele é "uma escapada na ociosidade de um psicólogo." (GD/CI, Prefácio, 1, KSA $6.58(\mathrm{SM}))^{7}$. Não se trata, pois, de criticar a ociosidade em nome do trabalho. Esse tipo de oposição dificilmente encontraria lugar no contexto das páginas iniciais do Crepúsculo dos ídolos. Bem ao contrário, trata-se de elogiar a ociosidade, indicando que ela é ainda mais indispensável quando se trata de dedicar-se a uma tarefa de grande envergadura, como a de transvalorar todos os valores. Não é,

7 Na verdade, essa frase só ganharia inteiramente sentido se o livro levasse o título "Lazer de um psicólogo". Numa certa medida, Nietzsche resiste em abandonar o título que escolhera de início para o que iria converter-se no Crepúsculo dos ídolos. Cf. nessa direção Nachlass/FP 1888, 22 [6], KSA 13.586, onde Nietzsche anota vários títulos para seu livro, sendo que praticamente todos eles apresentam a palavra "psicólogo".

48 | Cad. Nietzsche, Guarulhos/Porto Seguro, v.41, n.2, p. 45-62, maio/agosto, 2020. 
pois, à concepção tradicional de psicologia que remete essa primeira sentença, mas à própria concepção nietzschiana de psicologia.

No Crepúsculo dos ídolos, Nietzsche esclarece que a psicologia, tal como a concebe, não se confunde com a mera observação - seja ela simplesmente reflexiva ou voltada para o mundo circundante. Opondo-se à divisa socrática, ele não admite que a busca interna possa dar diretrizes para a ação. Essa recusa constitui, por certo, uma das razões que o levam a afirmar que a psicologia deve vincular-se estreitamente à história. Essa ideia, aliás, já aparece no primeiro volume de Humano, demasiado humano. ${ }^{8}$ Então, ao exprimir-se sobre o estudo psicológico, Nietzsche insiste na necessidade de romper com a metafísica no exame das questões morais. Em vez de deduzir os fenômenos morais dos princípios gerais da metafísica, a psicologia deveria comprometer-se em inscrevê-los num quadro histórico, perguntando por sua proveniência e sua história. Em 1878, Nietzsche já se nega a considerar a psicologia uma parte da filosofia geral; assim é que rejeita a ideia de que os fenômenos morais estejam fundados na noção de alma. Bem ao contrário, no seu entender, eles surgem, modificam-se e, por vezes, desaparecem.

Em 1888, Nietzsche vai além. Com o intuito de alertar seus leitores para tomarem a precaução de evitar uma eventual identificação entre a atitude do psicólogo e a do observador, ele exorta-os no Crepúsculo dos Ídolos a "nunca observar por observar! Isso resulta num defeito de ótica, num estrabismo, em algo forçado e excessivo." (GD/CI, Incursões de um extemporâneo, 7, KSA 6.115 (SM)) Desprezando o simples acúmulo de dados, não aceita que os

8 Cf. em particular HH I 37, KSA 2.59s (SM), onde lemos: “O renascimento da observação psicológica tornou-se necessário e não se pode mais poupar a humanidade da visão cruel da mesa de dissecação da psicologia, de seus escalpelos e de suas pinças; pois, aqui ordena essa ciência, que investiga a origem e a história dos chamados sentimentos morais e, à medida que progride, deve colocar e resolver os complexos problemas sociológicos; ignorando-os completamente, a antiga filosofia sempre se esquivou, através de pobres subterfúgios, da investigação sobre a origem e história dos sentimentos morais". 
Marton, S.

fatos por si sós possam orientar a conduta humana. Tanto é que, num fragmento póstumo desse período, afirma:

desconfiamos de todos os que contemplam o próprio umbigo, tãosomente pela razão de que a auto-observação nos parece uma forma de degenerescência do gênio psicológico, um ponto de interrogação quanto ao instinto do psicólogo. (Nachlass/ FP 1888, 14 [28], KSA 13.231 (SM) $)^{9}$

Nem a introspecção nem o livro do mundo estão em condições de contribuir para estabelecer o critério de avaliação das avaliações. É em Assim falava Zaratustra que Nietzsche introduz a noção de valor. Então, ele passa a identificar a psicologia ao procedimento genealógico. Ao psicólogo tocaria questionar o valor dos valores morais, examinando as condições e circunstâncias de sua proveniência e modificações. A ele caberia relacionar os valores com as avaliações de que procedem e investigar de que valor estas partiram para criálos. Em suma, ao psicólogo Nietzsche atribui a tarefa de avaliar as avaliações. Para tanto, ele terá de dispor de um critério que, por sua vez, não possa ser avaliado.

Mas Nietzsche não se empenhará em perguntar pela verdade ou falsidade das diferentes avaliações. Se ele se recusa a lançar mão dos procedimentos lógicos usuais, é porque pensa que o fariam cair num círculo vicioso. Uma vez que a própria verdade é um valor, não se poderia tomá-la como o critério de avaliação das avaliações. Não é, pois, no domínio da teoria do conhecimento que se deve considerar a questão, mas no âmbito da axiologia. Deslocando por completo o problema da avaliação das avaliações, Nietzsche se põe em busca de um critério que não se apresente como resultado de uma avaliação. É assim que ele o formula no Crepúsculo dos ídolos:

9 Cf. também Nachlass/FP 1888, 14 [27], KSA 13.230 (SM), onde lemos: "nós, psicólogos do futuro, somos pouco inclinados à auto-observação, tomamos quase por um sinal de degenerescência o fato de um instrumento procurar 'conhecer-se a si mesmo'." Acerca do estatuto da psicologia na obra nietzschiana, $c f$. entre outros Kaufmann, 1978, pp. 261-275; Pippin, 2010; Marton, 2010, em particular o segundo capítulo.

50 | Cad. Nietzsche, Guarulhos/Porto Seguro, v.41, n.2, p. 45-62, maio/agosto, 2020. 
Seria preciso ter uma posição fora da vida e, por outro lado, conhecê-la tão bem quanto um, quanto muitos, quanto todos, que a viveram, para poder em geral tocar o problema do valor da vida: razões bastantes para se compreender que este problema é um problema inacessível a nós. (GD/ CI, Moral como contranatureza, 5, KSA 6.86 (RRTF) $)^{10}$

No quadro do procedimento genealógico, as noções de vida e valor se acham intimamente ligadas. Moral, política, religião, ciência, arte, filosofia: qualquer apreciação de qualquer ordem deve passar pelo crivo da vida. Submeter ideias ou atitudes ao exame genealógico é o mesmo que inquirir se são signos de plenitude de vida ou de sua degeneração, ou seja, equivale a perguntar se contribui para favorecer a vida ou obstruí-la. Em suma, avaliar uma avaliação significa questionar se é sintoma de vida ascendente ou declinante.

\section{II.}

É enquanto psicólogo que Nietzsche tratará da décadence nos textos de 1888. Nos dois primeiros parágrafos de $O$ Anticristo, ele elucida a perspectiva que conta adotar. Afirmando que "nós somos hiperbóreos", sublinha sua distância em relação ao "homem moderno"; em seguida, mostra que sua maneira de conceber os valores "bom" e "ruim" constitui o reverso da moral cristã. Então, dedica-se a avaliar os valores apregoados pelo cristianismo e relacioná-los com a perspectiva que os estabeleceu. Ao que provoca a enfermidade, os cristãos atribuíram o valor "bom'; ao que resulta da plenitude, o valor "mau". Por fim, empenha-se em avaliar a avaliação cristã.

$10 \mathrm{Cf}$. outra formulação do critério de avaliação das avaliações em GD/CI, O problema de Sócrates, 2, KSA 6.68 (tradução de Rubens Rodrigues Torres Filho, designado a partir de agora RRTF): "É preciso estender os dedos, completamente, nessa direção e fazer o ensaio de captar essa assombrosa finesse - de que o valor da vida não poder ser avaliado. Por um vivente não, porque este é parte interessada, e até mesmo objeto de litígio, e não juiz; por um morto não, por uma outra razão." 
Marton, S.

No fim das contas, é a enfermidade que constitui a condição de possibilidade do cristianismo. ${ }^{11}$

No entender de Nietzsche, criação do apóstolo Paulo, a religião cristã veio impor o reino dos fracos e dos oprimidos. Sobrepujando a aristocracia guerreira da Antiga Grécia, sacerdotes e teólogos converteram a preeminência política em preeminência espiritual. Enquanto valor aristocrático, "bom" se identificava a nobre, belo, feliz; tornando-se valor religioso, passa a equivaler a pobre, miserável, impotente, sofredor, piedoso, necessitado, enfermo. Dominados pelo "ódio instintivo contra a realidade", teólogos e sacerdotes operaram uma inversão de valores. É nesse contexto que Nietzsche escreve: "minha afirmação é que todos os valores nos quais a humanidade enfeixa agora sua mais alta desejabilidade são valores de décadence." (AC/AC 6, KSA 6.172 (RRTF) $)^{12}$. Essa afirmação dá a entender que a décadence não se revela somente na moral cristã; bem mais, ela não se mostra apenas no domínio moral. Tanto é que, no prefácio ao Caso Wagner, Nietzsche sublinha que “'Bem e Mal' é apenas uma variante" do problema da décadence (Cf. WA/CW, Prefácio, KSA $6.11(\mathrm{SM}))$.

Além de criticar o cristianismo do ponto de vista moral, Nietzsche vai combatê-lo enquanto religião. Fazendo uma análise detida da noção cristã de Deus em $O$ Anticristo, ele mostra que essa noção traz à cena um "Deus degenerado" que não passa de uma "antítese da vida" (AC/AC 18, KSA 6.185 (SM)); assim concebido, o Deus cristão é um "híbrido produto decadente, feito de zero, conceito e contradição, em que têm sanção todos os instintos da décadence"

110 Anticristo atraiu as atenções de teólogos e historiadores das religiões, como mostram os estudos de Köster 1981/82, pp. 615-685 e Schellong 1989, pp. 338-358. Mas também veio a constituir objeto de exame privilegiado para os estudiosos do pensamento nietzschiano, como é o caso de Marton 2014(a), em particular o capítulo 11; Sommer 2000; Stegmaier 1992, pp. 163-183; Salaquarda 1973, pp. 91-136.

12 Cf. também EH, Por que sou um destino, 7, KSA 6.372 (SM), onde lemos: "a humanidade mesma estaria em décadence? Sempre esteve? - o que é certo é que a ensinaram como valores supremos unicamente valores de décadence."

52 | Cad. Nietzsche, Guarulhos/Porto Seguro, v.41, n.2, p. 45-62, maio/agosto, 2020. 
(AC/AC 19, KSA 6.185 (SM)) 13. Se Nietzsche aprecia o budismo, porque seria mais realista do que o cristianismo, não se priva, porém, de atacá-lo, afirmando que ambos, budismo e cristianismo, "estão juntos como religiões niilistas - são religiões da décadence" (AC/ AC $§ 20$, KSA $6.186(\mathrm{SM}))^{14}$.

Assim como se volta contra as formas de expressão da décadence na religião, Nietzsche também combaterá as que se acham presentes na filosofia. Entre os alvos de ataque por ele visados, encontra-se o imperativo categórico de Kant. A seu ver, impondo ao indivíduo a lei de reciprocidade, ele o levaria a agir "como autômato do "dever". Dissociando a ação e o prazer, constituiria "precisamente a receita da décadence" (AC/AC 11, KSA 6.177 (SM)). Schopenhauer, por sua vez, teria feito da filosofia a negação da vida. Na ótica nietzschiana, privilegiando a compaixão, que nada mais é do que "a prática do niilismo", teria instituído "um instrumento capital para a intensificação da décadence" (AC/AC 7, KSA 6.173 (RRTF)) ${ }^{15}$.

Contudo, não é apenas no pensamento kantiano e na filosofia schopenhaueriana que a décadence se manifestaria. No entender de Nietzsche, ela já está presente nos gregos. Levando adiante o trabalho de idealização a ponto de inventar um mundo essencial, imutável e eterno em oposição ao mundo em que nos achamos aqui e agora, Platão seria responsável por fazer da filosofia grega "a décadence do instinto grego". (GD/CI, O que devo aos antigos, 2, KSA 6.155s (RRTF)) Mas na Grécia antiga, seria sobretudo com Sócrates que a décadence se expressaria. Não é por acaso que, no capítulo intitulado "O problema de Sócrates" do Crepúsculo dos ídolos, Nietzsche não tem a intenção simplesmente de analisar o caráter problemático

13 Cf. também EH, Genealogia da Moral, KSA 6.353, onde Nietzsche considera o ideal ascético como "um ideal de décadence".

14 Cf. também AC/AC 42, KSA 6.215 e WA/CW, "Post-Scriptum", KSA 6.43. Para uma análise aprofundada das relações entre décadence e niilismo, $c f$. por exemplo Johnson 2014, pp. 31s e Volpi 2005, pp. 97-119.

15 Cf. também WA/CW § 4, KSA 6.21 e GD/CI, Incursões de um extemporâneo, § 37, KSA 6.136s.

Cad. Nietzsche, Guarulhos/Porto Seguro, v.41, n.2, p. 45-62, maio/agosto, 2020. | 53 
Marton, S.

dessa personagem; bem ao contrário, quer sublinhar que conta tomar Sócrates enquanto problema, melhor ainda, que pretende encará-lo como aquele que encarna um problema.

Não podemos deixar de notar a semelhança marcante entre esse capítulo e $O$ caso Wagner. No Crepúsculo dos ídolos, Nietzsche mostra que por meio da "superfetação do lógico" e dessa maldade raquítica, Sócrates promove a expansão anormal da razão e, por conseguinte, o enfraquecimento das pulsões. (Cf. GD/CI, O problema de Sócrates, 4, KSA 6.69) No Caso Wagner, revela que, por meio da melodia infinita, o compositor leva ao exagero dos sentimentos, ao êxtase, e, por conseguinte, ao extremo esgotamento. Nos dois casos, ainda que por vias distintas, instalam-se perturbações no organismo, a ponto de levá-lo a perder o equilíbrio. Enquanto Sócrates exprime a décadence na filosofia, Wagner a expressa na música. ${ }^{16}$ Mas, quando se trata de contextualizá-la, Nietzsche irá associá-la ao grande mal-estar que estaria em curso em sua época. É nesse sentido que, bem mais que o diagnóstico do compositor da Tetralogia, O caso Wagner apresenta o diagnóstico de um tipo que corporifica a própria décadence. No fim das contas, "Wagner resume a modernidade" (WA/CW, Prefácio, KSA 6.12) ${ }^{17}$.

Valeria lembrar que a análise das "ideias modernas" é um dos propósitos que Nietzsche persegue em grande parte de seus escritos. Nelas, denuncia o modo de proceder dos ressentidos, critica a imposição do que é uniforme, ataca o reino do animal de rebanho. É desse ponto de vista que julga acontecimentos históricos, correntes de ideias, sistemas de governo. É também nesses termos que considera a

16 Acerca das relações entre décadence e arte, $c f$. entre outros Reschke 2008, pp. 203-226, e MüllerLauter 1999, pp. 11-30.

17 Em várias passagens, Nietzsche afirma que Wagner é o artista da décadence. Cf. por exemplo WA/CW 4 e $\$ 5$, KSA 6.21; WA/CW, Segundo Pós-Escrito, KSA 6.46; AC/AC 7, KSA 6.174. A esse propósito, $c f$. entre outros Sommer 2017; Campioni 2016, em particular, pp. 315-326; Marton 2014(b), pp. 199-225.

54 | Cad. Nietzsche, Guarulhos/Porto Seguro, v.41, n.2, p. 45-62, maio/agosto, 2020. 
democracia, o socialismo, o anarquismo; é dentro desses parâmetros que os avalia.

Mas que não exista, no pensamento de Nietzsche, uma teoria política acabada, salta aos olhos de quem entra em contato com a sua obra. ${ }^{18}$ Nem por isso o filósofo deixou de refletir sobre as questões relativas ao poder. Em seus escritos, são frequentes as vezes em que se detém no exame das relações entre o indivíduo e o Estado e também aquelas em que se empenha em analisar o Segundo Reich e Bismarck, o sufrágio universal e os exércitos nacionais, os partidos políticos e a situação da imprensa, o desaparecimento das nações e a unificação da Europa. Tanto temas centrais da filosofia política quanto problemas candentes da época atraem a sua atenção. Nem uns nem outros, no entanto, recebem tratamento especial. Nietzsche não se pretende teórico do poder, no sentido estrito da palavra, e tampouco se quer analista político. Embora atento a essa ordem de questões, não lhes confere estatuto próprio, não as enquadra num domínio particular do conhecimento nem delas trata com metodologia específica. Ao contrário, em sua obra, a política aparece estreitamente vinculada à moral e à religião; melhor ainda: política, moral e religião constituem ponto nodal em seu pensamento. Intimamente ligadas, integram um campo de investigação mais amplo: são objeto da crítica dos valores.

Essas considerações permitem compreender que, no Crepúsculo dos ídolos, Nietzsche caracterize "a democracia moderna, inclusive suas meias realidades, como o 'Império alemão', como forma de declínio do Estado (Verfallsform des Staats) (GD/CI, Incursões de um extemporâneo, 39, KSA 6.141 (SM))". Também permitem compreender que considere o conceito moderno de liberdade "um sintoma de décadence" e defina o progresso moderno como "a marcha do caranguejo", ou seja, "avançar passo a passo na décadence (GD/CI, Incursões de um extemporâneo, 41 e § 43, KSA 6.143s (RRTF))”. É

18 Acerca da concepção nietzschiana de política, $c f$. entre outros Conway 2013, pp. 25-39 e Denat 2013, pp.41-71. 
Marton, S.

ainda do ponto de vista da crítica dos valores que Nietzsche encara os estudos sociológicos no Crepúsculo dos ídolos. Assim é que afirma que sua objeção "contra a inteira sociologia na Inglaterra e na França continua a ser que ela só conhece por experiência formações sociais de caducidade (Verfalls-Gebilde der Societät) (GD/CI, Incursões de um extemporâneo, § 37, KSA 6.138 (RRTF))".

Nada escapa ao olhar crítico de Nietzsche. Enquanto psicólogo, ele diagnostica as formas de expressão da décadence na moral, religião, filosofia, política, sociologia, arte, música, literatura. ${ }^{19} \mathrm{Bem}$ mais, estima que a décadence é uma "tendência hostil à vida (GD/ CI, Incursões de um extemporâneo, 50, KSA 6.152 (SM))". Tanto é que a detecta em todo um período histórico e em todo um continente, pondo em evidência sua presença no século XIX na Europa (WA/ $\mathrm{CW} \S 5, \mathrm{KSA} 6.22(\mathrm{SM}))^{20}$.

\section{III.}

Nesse momento da nossa investigação, seria preciso inquirir o que Nietzsche entende pela expressão "fórmula da décadence", que ele introduz no Crepúsculo dos ídolos e em $O$ Anticristo. Num primeiro momento, somos levados a interpretar essa expressão como uma tentativa de sintetizar os elementos que decorrem das análises precedentes. Dessa perspectiva, a fórmula da décadence remete aos valores niilistas, aos sintomas de fraqueza, aos tipos que encarnam o declínio. Mas para tentar apreender o sentido preciso da ideia que essa expressão designa, torna-se indispensável analisar as três passagens em que ela aparece.

No segundo capítulo do Crepúsculo dos ídolos, Nietzsche empenha-se em explorar "O problema de Sócrates". Então, procura

19 Cf. WA/CW 7, KSA 6.28, onde Nietzsche aproxima Wagner dos irmãos Goncourt quanto ao estilo, e AC/AC 7, KSA 6.174, onde se exprime sobre a décadence literária e artística, referindo-se a Tolstói e Wagner.

20 A esse propósito, $c f$. entre outros Horn 2000.

56 | Cad. Nietzsche, Guarulhos/Porto Seguro, v.41, n.2, p. 45-62, maio/agosto, 2020. 
examinar um tipo décadent que sempre foi visto como alguém que conta entre os mais sábios de todos os tempos. E isso implica auscultar o consensus sapientium, para mostrar que, pondo-se de acordofisiologicamente, os mais sábios de todos os tempos exprimem juízos de valor sobre a vida - e mesmo contra ela. Então, Nietzsche faz ver que Sócrates foi um plebeu, um homem feio, um criminoso, um monstro. Em detrimento do gosto grego, ele impôs a dialética. Com Sócrates, essa arma nas mãos dos fracos converte-se numa forma de vingança. Se essa personagem se mostra repulsiva sob todos esses aspectos, ela também se revela fascinante, ao encarnar uma espécie de degenerescência, que, na sua época, se propagava por toda parte em Atenas. Contra a anarquia dos impulsos que estaria então em curso, Sócrates estabelece o império da racionalidade. Apresentandose como médico, tenta fazer guerra à décadence; enganando-se a si mesmo, prescreve como remédio o combate aos instintos. Enquanto tipo décadent, Sócrates sabia que era doente. Desejando a morte, a única cura possível no seu caso, suicidou-se. É nesse contexto que Nietzsche afirma: "Ter de combater os instintos - eis a fórmula para a décadence (GD/CI, O problema de Sócrates, 11, KSA 6.73 (RRTF))". Na medida em que o ser humano nada mais é do que uma configuração de impulsos, combater os instintos equivale a lutar contra a própria vida.

Outra passagem do Crepúsculo dos ídolos traz novas elucidações sobre o que Nietzsche entende pela expressão "fórmula da décadence". No capítulo "Incursões de um extemporâneo", ele faz a "crítica da moral da décadence", examinando um de seus principais pilares: o altruísmo. Então, afirma: "Escolher por instinto o que é prejudicial para si, ser atraído por motivos 'desinteressados', isso quase fornece a fórmula da décadence (GD/CI, Incursões de um extemporâneo, § 35, KSA 6.133 (SM))". Duas ideias exigem aqui a nossa atenção. Por um lado, ao empregar o vocábulo "quase", Nietzsche dá a entender que o altruísmo não constitui a fórmula completa da décadence: ele é apenas um de seus ingredientes. Por outro, ao afirmar que o altruísmo é uma escolha instintiva, ele destaca um novo elemento da sua concepção 
Marton, S.

de décadence: aquele que a associa a uma determinada condição fisiopsicológica. Tornar-se altruísta é um sinal de "desagregação dos instintos"; por não poder mais ser egoísta, o homem se volta para os outros. ${ }^{21}$ Mas, em vez de constatar que não vale mais nada, ele passa a afirmar que é a própria vida que não vale nada. Com isso, contamina toda a sociedade, favorecendo o aparecimento da religião cristã e, mais tarde, a filosofia schopenhaueriana.

É em $O$ Anticristo que se encontra a terceira passagem em que aparece a expressão "fórmula da décadence". No parágrafo 15, Nietzsche examina as idealizações que o cristianismo teria promovido. No seu entender, ele teria inventado causas imaginárias: "Deus", "alma", "eu”, "espírito", "vontade livre"; teria fabricado efeitos imaginários: "pecado", "redenção", "clemência", "remissão dos pecados"; teria forjado seres imaginários: "Deus", "espíritos", "almas"; teria concebido uma ciência da natureza imaginária, porque antropocêntrica; teria estabelecido uma psicologia imaginária, ao recorrer ao "arrependimento", "remorso de consciência", "tentação do diabo", "proximidade de Deus"; teria criado uma teologia imaginária, introduzindo ideia como "o reino de Deus", "o Juízo Final", "a vida eterna". Em suma, o cristianismo teria imposto um "puro mundo de ficções" engendrado pelo "ódio contra o natural (AC/AC 15, KSA 6.181 (RRTF))". Foi através da mentira que ele procurou escapar da realidade.

Não podemos deixar de salientar que, à diferença da maneira habitual de proceder que se limita a encarar a mentira do ponto de

21 No Ecce Homo, Nietzsche encara o trabalho que o levou a tornar-se o que é como "uma obra prima na arte da autoconservação - do egoísmo" (EH, Por que sou tão esperto, 9, KSA 6.293 (SM)). Redefinindo por completo a noção de egoísmo, ele vem recusar a concepção moderna de sujeito. Concebido como substrato que possui certas propriedades, desenvolve diversas atividades e produz vários efeitos, “o sujeito não é nada além de uma ficção (Nachlass/FP 1887, 9 [108], KSA 12.398 (SM))". Entendido como um todo independente, completo, idêntico a si mesmo, permanente e unitário, "o ego é tão-somente um 'embuste superior', um 'ideal' (EH, Por que escrevo livros tão bons, § 5, KSA 6.305 (SM))". No quadro desse egoísmo sem ego, não há lugar para um sujeito que se mantém sempre o mesmo em sua individualidade. Enquanto força organizadora, seu instinto de conservação fez em segredo o trabalho de formar uma configuração pulsional destinada à tarefa de transvalorar os valores.

58 | Cad. Nietzsche, Guarulhos/Porto Seguro, v.41, n.2, p. 45-62, maio/agosto, 2020. 
vista moral, Nietzsche a inscreve num outro quadro. É precisamente o que ele revela na definição que apresenta: "Denomino mentira: recusar ver o que se vê, recusar ver algo como se vê: pouco importa que a mentira se dê diante de testemunhas ou sem testemunhas (AC/AC 55, KSA 6.238 (SM))". Mentirosa, a interpretação que falseia não é tributária de uma falta de conhecimento, que impediria o intérprete de ver o que se vê; ela não se deve tampouco a uma eventual deficiência de sua capacidade cognitiva, que o prejudicaria no seu contato com o que o cerca. A interpretação que falseia é antes de mais nada uma tentativa de autoengano. Foi desse modo que os sacerdotes e teólogos cristãos se lançaram numa empresa de grande envergadura: a corrupção dos instintos.

Nesse parágrafo de $O$ Anticristo, Nietzsche elucida o que entende por essa expressão: "Denomino corrompido um animal, uma espécie, um indivíduo, quando perde seus instintos, quando escolhe, quando prefere o que lhe é pernicioso (AC/AC 6, KSA 6.172 (RRTF))". Exemplo acabado da corrupção dos instintos, os sacerdotes e teólogos cristãos dedicaram-se a disseminar a enfermidade; assim é que, propagando valores contrários à plenitude, à exuberância, à afirmação da própria vida, empenharam-se em fazer do ser humano um animal enfermo. Incapazes de encarar a realidade, procuraram camuflar o sofrimento por meio de um mundo de puras ficções. É então que Nietzsche conclui:

Mas sofrer com a efetividade significa ser uma efetividade malograda... A preponderância dos sentimentos de desprazer sobre os sentimentos de prazer é a causa daquela fictícia moral e religião: uma tal preponderância, porém, fornece a fórmula para décadence... (AC/AC $\S 15$, KSA $6.182(\mathrm{RRTF}))^{22}$

22 Vale lembrar o comentário léxico de Rubens Rodrigues Torres Filho em Nietzsche, 1978, p. 197, nota 2: "Wirklichkeit - termo usual alemão para designar o 'real', a 'realidade'; do verbo wirken (fazer efeito), que em linguagem filosófica designa, especificamente, a atuação da causa (eficiente) na produção do efeito (Wirkung). Nietzsche faz questão dessa derivação, já desde o texto de 1873 em que cita, a propósito de Heráclito, esta passagem de Schopenhauer: 'Causa e efeito são, portanto, toda a essência da matéria. Seu ser é seu efetuar-se. É com o maior acerto, portanto, que em alemão o conjunto de tudo o que é material é denominado efetividade, palavra que o designa muito melhor do que realidade' (Cf. A filosofia na época trágica dos gregos § 5)." 
Marton, S.

IV.

Os elementos então reunidos permitem-nos apontar dois resultados. Por um lado, observamos que, se a expressão "fórmula da décadence" remete aos valores niilistas, aos sintomas de fraqueza, aos tipos que encarnam o declínio, é porque ela comporta a ideia de que o ser humano é uma configuração fisiopsicológica, de sorte que combater os instintos, lutar contra os impulsos, é lutar contra si mesmo. Por outro, notamos que a "fórmula da décadence" designa uma configuração fisiopsicológica determinada: a que se mostra incapaz de aceitar que a dor não constitui uma objeção à vida, a que não pode tolerar que o sofrimento é parte integrante da existência. É precisamente nisso que consiste o seu malogro.

\title{
Nietzsche: From psychological Analysis to the "Formula of the Décadence"
}

\begin{abstract}
Having clarified the Nietzschean conception of psychology, this article pursues a double objective: on the one hand, to investigate the psychological analysis of the phenomena of décadence and, on the other, to elucidate what the expression "formula of décadence" means in the texts of 1888.
\end{abstract}

Keywords: psychology, value, evaluation, décadence.

60 | Cad. Nietzsche, Guarulhos/Porto Seguro, v.41, n.2, p. 45-62, maio/agosto, 2020. 


\section{Referências}

CAMPIONI, Giuliano. Nietzsche e o espírito latino. São Paulo: Edições Loyola, 2016. (Coleção Sendas \& Veredas)

CONWAY, Daniel. Política e decadência: o envolvimento crítico de Nietzsche com a modernidade europeia. In: Cadernos Nietzsche 32, pp. 25-39, 2013.

DENAT, Céline. F. Nietzsche ou a "política" como "antipolítica". In: Cadernos Nietzsche 32, pp. 41-71, 2013.

HORN, Anette. Nietzsches Begriff der "décadence": Kritik und Analyse der Moderne. Berlin: Peter Lang, 2000.

JOHNSON, Dirk. Nihilismus als Logik der Décadence. In: Nietzsche-Studien 43, pp. 31-32, 2014.

KAUFMANN, Walter. Nietzsche als der erste grosse Psychologue. In: NietzscheStudien 7, pp. 261-275, 1978.

KÖSTER, Peter. Nietzsche-Kritik und Nietzsche-Rezeption in der Theologie des 20. Jahrhunderts. In: Nietzsche-Studien 10/11, pp. 615-685, 1981/82.

MARTON, Scarlett. Nietzsche e a arte de decifrar enigmas. Treze conferências europeias. São Paulo: Edições Loyola, 2014(a). (Coleção Sendas \& Veredas)

. Modernidade e décadence. Wagner e a cultura filisteia. In: Marton, Scarlett; Branco, Maria; Constâncio, João (orgs.). Sujeito, décadence e arte. Nietzsche e a modernidade. Lisboa: Tinta da China, pp. 199-225, 2014(b).

. Nietzsche: das forças cósmicas aos valores humanos. Belo Horizonte: $3^{\text {a }}$ ed., 2010.

MONTINARI, Mazzino. Nietzsche lesen: Die Götzen-Dämmerung. In: NietzscheStudien 13, pp. 69-79, 1984.

MÜLLER-LAUTER, Wolfgang. Artistische décadence als physiologische décadence: zu Friedrich Nietzsches später Kritik an Richard Wagner. In: MÜLLERLAUTER, Wolfgang. Über Freiheit und Chaos. Berlim: De Gruyter, pp. 1-23, 1999; em português, Décadence artística enquanto décadence fisiológica. A propósito da crítica tardia de Friedrich Nietzsche a Richard Wagner. Trad. Scarlett Marton. In: Cadernos Nietzsche 6, pp. 11-30, 1999. 
Marton, S.

NIETZSCHE. Sämtliche Werke. Kritische Studienausgabe in 15 Bänden (KSA). Berlim: De Gruyter, 1988.

. Sämtliche Briefe. Kritische Studienausgabe in 8 Bänden (KSB). Berlim: De Gruyter, 1986.

. Obras incompletas. Trad. Rubens Rodrigues Torres Filho. São Paulo: Abril Cultural, 2a ed., 1978 (Coleção "Os Pensadores").

PIPPIN, Robert. Nietzsche, Psychology, and First Philosophy. Chicago: University of Chicago Press, 2010.

RESCHKE, Renate. Warum Kultur von Zeit zu Zeit an sich selbst zugrunde geht... Friedrich Nietzsche, die Décadence und die Ambivalenz einer ästhetisch dominierten Kultur. In: SOMMER, Andreas Urs (org.). Nietzsche - Philosoph der Kultur(en)? Berlin: De Gruyter, pp. 203-226, 2008.

SALAQUARDA, Jörg. Der Antichrist. In: Nietzsche-Studien 2, pp. 91-136, 1973.

SCHELLONG, Dieter. Einige Interpretationsfragen zu Nietzsches Verurteilung des Christentums. In: Nietzsche-Studien 18, pp. 338-358, 1989.

SOMMER, Andreas Urs. Nietzsche, Wagner e a decadência. Trad. Fernando R. de Moraes Barros. In: Cadernos Nietzsche 38 vol. 1, pp. 11-25, 2017. 2000 .

STEGMAIER, Werner. Nietzsches Kritik der Vernunft seines Lebens. Zur Deutung von "Der Antichrist" und "Ecce homo". In: Nietzsche-Studien 21, pp. 163183, 1992.

VOLPI, Franco. Le nihilisme comme logique de la décadence: Niettzsche lecteur de Bourget. Trad. Alessio Moretti. In: MATTÉI, Jean-François (org.). Nietzsche et le temps des nihilismes. Paris: PUF, pp. 97-119, 2005.

WOLFF, Christian. Psychologia Rationalis. Nova York: G. Olms, 1972.

Enviado: 22/04/2020

Aceito: 22/05/2020

62 | Cad. Nietzsche, Guarulhos/Porto Seguro, v.41, n.2, p. 45-62, maio/agosto, 2020. 